\title{
Effective measures for combating drink-driving offenses: an attitudinal
}

\section{model for Hong Kong}

\author{
Y.C. $\mathrm{Li}^{\mathrm{a}}{ }^{*}$, N.N. Sze ${ }^{\mathrm{b}}$ and S.C. Wong ${ }^{\mathrm{a}}$ \\ ${ }^{a}$ Department of Civil Engineering, The University of Hong Kong, Pokfulam Road, Hong \\ Kong; ${ }^{b}$ Department of Civil and Natural Resources Engineering, University of Canterbury, \\ Christchurch, New Zealand
}

\begin{abstract}
In Hong Kong, legal limits on the concentration of alcohol permitted in drivers' blood, urine, and breath were introduced in 1995. Later legislation empowered the police to conduct random breath tests (RBTs) without the need for suspicion. Although drink driving accounts for a relatively small portion of the traffic accidents in Hong Kong, the average killed and seriously injured rate for drink-driving accidents is higher than that for overall traffic accidents. From time to time, there are calls for heavier penalties such as longer prison sentences and driving disqualification periods for drink drivers, particularly those who cause severe injury and death. However, no consensus has been reached on the actual effectiveness of severe penalties in combating drink-driving offenses. In this study, a self-administrated, mail-back questionnaire including six stated preference games was conducted to evaluate drivers' perceptions of the current levels of penalties against drink-driving offenses. The game measured the associations between the propensity to drive after drinking and penalty levels. The results of a mixed logistic regression model revealed that the presence of an RBT checkpoint and an increase in driving-offense points and the durations of license disqualification and imprisonment correlated positively with an increase in the deterrent effects of measures taken to combat drink driving.
\end{abstract}

Keywords: Traffic safety; Drink-driving; Random breath test; Stated preference survey; mixed logistic regression.

\section{Introduction}

In Hong Kong, drink-driving offenses are often overlooked by the public, in contrast to other criminal offenses such as sexual and property offenses. As in many other countries, drink driving increases the risk of road traffic accidents, particularly killed and seriously injured (KSI) accidents (Tsui et al., 2010; Li et al., 2013a, 2013b). The World Health Organization (WHO) reported that on average, 20\% of drivers killed on the roads in high-income countries are alcohol impaired. The proportions in low-income countries are even higher, ranging from $33 \%$ to $69 \%$ (WHO, 2007). A local study illustrated that about $10.3 \%$ of all road traffic accidents involving death in Hong Kong are associated with alcohol (Cameron, 2004). Accident data for the 2007-2011 period from the Transport Department of Hong Kong revealed that 162 traffic accidents were related to drink driving, of which 32 (20\%) were KSI accidents (Transport Department, 2009a). Fortunately, the results of previous studies have indicated that appropriate enforcement strategies are effective in combating drink driving and reducing the risk of road traffic accidents (Ross, 1984; Wong et al., 2004; Tay, 2005a; Elvik and Christensen, 2007). Drink-driving offenses thus merit greater attention if road safety performance is to be enhanced.

*Corresponding author. Email: joeyliyc@hku.hk 
Monetary fines, demerit points, license disqualification, and imprisonment are the common penalties for combating driving offenses, including drink driving. In Hong Kong, a legal blood alcohol concentration (BAC) limit for drivers of $80 \mathrm{mg} / 100 \mathrm{ml}(0.08 \%)$ was introduced in 1995 and subsequently lowered to $50 \mathrm{mg} / 100 \mathrm{ml}(0.05 \%)$ in 1999, and any driver who commits a drink-driving offense is prosecuted. For the first conviction, the penalties include a deduction of 10 driving-offense points (DOPs), a maximum fine of HKD25,000 (USD1 is approximately equivalent to HKD7.8), a minimum license disqualification for six months, or imprisonment for three years. For a repeat conviction, the license disqualification period is extended to two years (Transport Department, 2009b). In 2009, the police were empowered to conduct random breath tests (RBTs) at the roadside. Since then, the number of prosecutions for drink driving has decreased from about 1,400 per year (from 2007 to 2008) to about 1,000 (in 2010). At the same time, the number of alcoholrelated crashes dropped by 60\% between 2008 and 2010 (Hong Kong Police Force, 2010). However, despite the remarkable reduction in alcohol-related crashes, there are still calls for heavier penalties to deter drink driving, especially in cases of repeat convictions and high alcohol consumption.

Deterrence theory is the central theme of various traffic management, control, and enforcement measures (Ross, 1984; Houston and Richardson, 2004), which aim to increase the certainty, severity, and celerity of penalties to deter poor driving behavior. Ross and Klette (1995) suggested that changes in penalty levels are effective in deterring drink-driving offenses. Numerous other studies have revealed that an increase in penalty levels and the strengthening of police enforcement result in improvements in road safety (Wong et al., 2004; Goldenbeld and Schagen, 2005; Tay, 2005a; Elvik and Christensen, 2007). However, other studies have argued that an increase in penalty levels may not necessarily result in a reduction in the road traffic accident risk (Ross and Klette, 1995, Ruhm, 1996; Montag, 2010; Ryeng, 2012). An Australian study reported that the risks of traffic accidents actually increased after the introduction of stricter drink-driving penalties (Briscoe, 2004). Hence, the introduction of a heavier penalty may only be suitable as a last resort to combat drink driving. Empirical evidence on the effects of heavier drink-driving penalties on road safety performance is limited. Houston and Richardson (2004) established a logit regression model to estimate the perceived values that drivers gave to penalties against drink-driving offenses. Lapham and Todd (2012) recently showed that the period of imprisonment correlated negatively with drivers' propensity to drink and drive. Nevertheless, an attitudinal model to measure the relation between driver demographics, driving experiences, and the deterrent effect of penalty levels, including fines, demerit points, license disqualification, and imprisonment, is essential.

Therefore, a self-administered mail-back questionnaire survey was conducted to measure drivers' attitudes toward the type and level of penalties that would deter drinkdriving offenses in Hong Kong. This was a stated preference (SP) experiment to gauge the trade-off that drivers make between different types of penalties. A mixed logistic regression model was built to identify possible factors, including demographics, driving experience, and driving habit, contributing to the associations between the propensity to drive after drinking and penalties.

\section{Method}

\subsection{Data collection}


The survey targeted all drivers holding valid driving licenses in Hong Kong. Data were collected through a self-administered mail-back questionnaire. Copies of the questionnaire were delivered at on-road parking areas and RBT checkpoints evenly and widely distributed in all districts of Hong Kong around the clock from March to December 2012. A total of 17,736 questionnaire scripts were distributed, and 736 completed questionnaires were received (response rate, $4.1 \%$ ).

The questionnaire comprised four parts: (i) basic information about the driver, (ii) trip characteristics at the time of questionnaire delivery, (iii) traffic offense record, and (iv) perceptions of the various penalties for combating drink-driving offenses. The first part collected information on the gender, age, education, personal income, and driving experience of the respondent. The second part collected information on the trip characteristics, including day of the week, time of day, geographical area, and vehicle type. The third part collected information on the driver's involvement in traffic offenses, traffic accidents, and RBTs during the preceding 12 months. Self-reports of drink or drug driving in the previous three months were also collected (Appendix). Table 1 presents a summary of the respondent characteristics. Of the 736 respondents, 503 (68.3\%) declared that they were drinkers, and $233(31.7 \%)$ declared that they were non-drinkers, which were comparable to the general drinking pattern of adults in Hong Kong (72.0\% drinkers and $28.0 \%$ non-drinkers) (Department of Health, 2011). The drinkers and non-drinkers had similar characteristics, but the drinkers had a higher prevalence of driving under the influence of alcohol and drugs (in the past three months, $14.0 \%$ had driven under the influence of alcohol and $35.4 \%$ had driven under the influence of drugs) than non-drinkers $(0.0 \%$ and $27.8 \%$ for the same categories, respectively).

Table 1 Descriptive statistics of the sampled drivers

\begin{tabular}{|c|c|c|c|}
\hline Factors & $\begin{array}{l}\text { Non-drinkers } \\
\quad(n=233)\end{array}$ & $\begin{array}{l}\text { Drinkers } \\
(n=503)\end{array}$ & $\begin{array}{c}\text { Total study } \\
\text { sample } \\
(\mathbf{n}=736) \\
\end{array}$ \\
\hline \multicolumn{4}{|l|}{ (i) Basic driver information } \\
\hline \multicolumn{4}{|l|}{ Gender } \\
\hline Female & $18.0 \%$ & $8.7 \%$ & $11.7 \%$ \\
\hline Male & $82.0 \%$ & $91.3 \%$ & $88.3 \%$ \\
\hline \multicolumn{4}{|l|}{ Age (years) } \\
\hline $18-34$ & $17.8 \%$ & $21.7 \%$ & $20.5 \%$ \\
\hline $35-44$ & $24.0 \%$ & $30.4 \%$ & $28.4 \%$ \\
\hline $45-54$ & $41.8 \%$ & $32.3 \%$ & $35.2 \%$ \\
\hline $55-64$ & $16.4 \%$ & $15.6 \%$ & $15.9 \%$ \\
\hline 65 or above & $2.7 \%$ & $1.4 \%$ & $1.8 \%$ \\
\hline \multicolumn{4}{|l|}{ Education } \\
\hline Primary & $14.4 \%$ & $11.4 \%$ & $12.3 \%$ \\
\hline Secondary & $59.4 \%$ & $51.5 \%$ & $54.0 \%$ \\
\hline Tertiary or above & $26.2 \%$ & $37.1 \%$ & $33.7 \%$ \\
\hline \multicolumn{4}{|c|}{ Monthly personal income (HKD) } \\
\hline Less than $\$ 10,000$ & $15.6 \%$ & $9.2 \%$ & $11.2 \%$ \\
\hline$\$ 10,000-\$ 14,999$ & $31.1 \%$ & $27.7 \%$ & $28.8 \%$ \\
\hline$\$ 15,000-\$ 24,999$ & $27.1 \%$ & $30.9 \%$ & $29.7 \%$ \\
\hline$\$ 25,000$ or above & $26.2 \%$ & $32.2 \%$ & $30.3 \%$ \\
\hline \multicolumn{4}{|l|}{ Driving experience (years) } \\
\hline $1-10$ & $29.5 \%$ & $30.7 \%$ & $30.3 \%$ \\
\hline
\end{tabular}




\begin{tabular}{|c|c|c|c|}
\hline $11-20$ & $29.5 \%$ & $33.1 \%$ & $32.0 \%$ \\
\hline $21-30$ & $30.8 \%$ & $26.5 \%$ & $27.8 \%$ \\
\hline 31 or above & $10.3 \%$ & $9.7 \%$ & $9.9 \%$ \\
\hline \multicolumn{4}{|c|}{ (ii) Questionnaire information } \\
\hline \multicolumn{4}{|l|}{ Day of the week } \\
\hline Weekday & $63.6 \%$ & $61.3 \%$ & $62.1 \%$ \\
\hline Weekend & $36.4 \%$ & $38.7 \%$ & $37.9 \%$ \\
\hline \multicolumn{4}{|l|}{ Time of day } \\
\hline $0700-1100$ & $26.5 \%$ & $19.6 \%$ & $21.8 \%$ \\
\hline $1100-1500$ & $20.0 \%$ & $24.3 \%$ & $22.9 \%$ \\
\hline $1500-1900$ & $16.7 \%$ & $12.9 \%$ & $14.1 \%$ \\
\hline $1900-2300$ & $24.7 \%$ & $30.6 \%$ & $28.7 \%$ \\
\hline $2300-0300$ & $9.8 \%$ & $11.0 \%$ & $10.6 \%$ \\
\hline 0300-0700 & $2.3 \%$ & $1.7 \%$ & $1.9 \%$ \\
\hline \multicolumn{4}{|l|}{ Geographical area } \\
\hline Hong Kong Island & $21.2 \%$ & $24.1 \%$ & $23.2 \%$ \\
\hline Kowloon & $47.9 \%$ & $49.8 \%$ & $49.2 \%$ \\
\hline New Territories & $30.9 \%$ & $26.2 \%$ & $27.6 \%$ \\
\hline \multicolumn{4}{|l|}{ Vehicle type } \\
\hline Non-commercial & $76.5 \%$ & $77.6 \%$ & $77.2 \%$ \\
\hline Commercial & $23.5 \%$ & $22.4 \%$ & $22.8 \%$ \\
\hline \multicolumn{4}{|l|}{ (iii) Traffic offense record } \\
\hline \multicolumn{4}{|c|}{$\begin{array}{l}\text { Prosecuted for traffic offense in the past } 12 \\
\text { months }\end{array}$} \\
\hline No & $66.1 \%$ & $61.8 \%$ & $63.2 \%$ \\
\hline Yes & $33.9 \%$ & $38.2 \%$ & $36.8 \%$ \\
\hline \multicolumn{4}{|c|}{$\begin{array}{l}\text { Involved in traffic accident in the past } 12 \\
\text { months }\end{array}$} \\
\hline No & $87.6 \%$ & $86.1 \%$ & $86.5 \%$ \\
\hline Yes & $12.4 \%$ & $13.9 \%$ & $13.5 \%$ \\
\hline \multicolumn{4}{|c|}{ Subjected to an RBT in the past 12 months } \\
\hline No & $76.5 \%$ & $72.8 \%$ & $74.0 \%$ \\
\hline Yes & $23.5 \%$ & $27.2 \%$ & $26.0 \%$ \\
\hline \multicolumn{4}{|c|}{ Drink driving in the past 3 months } \\
\hline No & $100.0 \%$ & $86.0 \%$ & $90.4 \%$ \\
\hline Yes & $0.0 \%$ & $14.0 \%$ & $9.6 \%$ \\
\hline \multicolumn{4}{|c|}{ Drug driving in the past 3 months ${ }^{\dagger}$} \\
\hline No & $72.2 \%$ & $64.6 \%$ & $67.0 \%$ \\
\hline Yes & $27.8 \%$ & $35.4 \%$ & $33.0 \%$ \\
\hline
\end{tabular}

Totals for all categories may not sum to 736 due to missing data.

RBT, random breath test.

${ }^{\dagger}$ Prevalence of driving under the influence of prescription medicine (legal drugs).

The last part of the questionnaire solicited the respondents' attitudes toward existing penalties against drink-driving offenses upon first conviction (i.e., a deduction of 10 DOPs, a maximum fine of HKD25000, maximum imprisonment for three years, and a minimum driving disqualification period of six months). A five-point scale was used in which 5 indicated "too high," 4 indicated "high," 3 indicated "moderate," 2 indicated "low," and 1 indicated "too low." Respondents who declared that they were drinkers were further exposed to six stated-preference (SP) games, in each of which they were asked whether they would drink 
given a hypothetical combination of drink-driving penalties (Refer to Question 17 in the Appendix).

\subsection{Stated preference design}

In SP surveys, a full factorial experimental design is commonly applied to examine the effects (both main and interaction) of all possible factors. However, it is not usually feasible to present all possible combinations of factor attributes when the number of factors and attributes increase in an SP survey. Therefore, an orthogonal fractional factorial design, a subset of a full factorial design, is recommended (Montgomery, 2001). The orthogonal fractional factorial design has been extensively used in a large variety of transport studies to determine drivers' preferences for numerous possible factor attributes, especially in mode choice studies (Bajwa et al., 2008; Bliemer and Rose, 2011; Rose et al., 2012). However, the application of such a design to road safety research has been rare. In this study, an orthogonal fractional factorial experimental design was applied to generate combinations of factor attributes for the association between drivers' propensity to drive after drinking and various penalty levels. Five factors were considered in the experimental design: (i) presence of an RBT checkpoint, (ii) monetary fine, (iii) DOPs, (iv) license disqualification period, and (v) imprisonment period. The presence of an RBT checkpoint had two levels (present or absent), whereas the four penalties had three levels. The current penalty level was adopted as one of the attribute levels for different penalties. The attribute levels of these factors are presented in Table 2.

Table 2 Factors and attributes in stated preference survey design

\begin{tabular}{lccc}
\multicolumn{1}{c}{ Factors } & \multicolumn{3}{c}{ Attributes } \\
\hline Presence of RBT checkpoints & No & Yes \\
Fine (HKD) & 5,000 & 10,000 & 25,000 \\
Driving offense points & 0 & 5 & 10 \\
Disqualification period (months) & 0 & 6 & 24 \\
Imprisonment period (months) & 0 & 12 & 36 \\
\hline
\end{tabular}

RBT, random breath test.

Eighteen combinations of monetary fines, DOPs, license disqualification periods, imprisonment periods, and the presence of RBT checkpoints were generated. In particular, as shown in Table 3 , the factors were assigned to an $L_{18}\left(2 \times 3^{4}\right)$ orthogonal array (Wang and Li, 2002, 2005). These 18 combinations were randomly segregated into 3 groups, each of which was then assigned to one of three sets of questionnaire scripts.

Table 3 Combinations of penalties presented in the proposed stated preference survey, based on the orthogonal fractional experiment design

\begin{tabular}{ccccccc}
\hline $\begin{array}{c}\text { Questionnaire } \\
\text { Set }\end{array}$ & $\begin{array}{c}\text { Experiment } \\
\text { Number }\end{array}$ & $\begin{array}{c}\text { Presence } \\
\text { of RBT } \\
\text { checkpoints }\end{array}$ & Fine & $\begin{array}{c}\text { Driving } \\
\text { offense } \\
\text { points } \\
\text { (HKD) }\end{array}$ & $\begin{array}{c}\text { License } \\
\text { disqualification } \\
\text { period } \\
\text { (months) }\end{array}$ & $\begin{array}{c}\text { Imprisonment } \\
\text { period }\end{array}$ \\
\hline 1 & 1 & No & 5,000 & 0 & 0 & (months) \\
\hline & 6 & Yes & 10,000 & 10 & 24 & 0 \\
& 8 & No & 25,000 & 5 & 24 & 12 \\
& 10 & Yes & 5,000 & 0 & 24 & 36 \\
& 15 & No & 10,000 & 10 & 0 & 12 \\
\hline 2 & 17 & Yes & 25,000 & 5 & 0 & 36 \\
\hline & 2 & No & 5,000 & 5 & 6 & 12
\end{tabular}




\begin{tabular}{ccccccc} 
& 4 & Yes & 10,000 & 0 & 0 & 12 \\
9 & No & 25,000 & 10 & 0 & 36 \\
& 11 & Yes & 5,000 & 5 & 0 & 0 \\
& 13 & No & 10,000 & 0 & 6 & 36 \\
\hline 3 & Yes & 25,000 & 10 & 6 & 0 \\
\hline 3 & No & 5,000 & 10 & 24 & 36 \\
& 5 & Yes & 10,000 & 5 & 6 & 0 \\
& 7 & No & 25,000 & 0 & 6 & 12 \\
& 12 & Yes & 5,000 & 10 & 6 & 12 \\
\hline
\end{tabular}

\subsection{Statistical analysis}

SPSS 20.0 statistical software was used to perform the statistical analyses in this study. An independent samples $t$-test was used to evaluate differences in the perceptions of drinkers and non-drinkers toward the existing penalty levels used to combat drink-driving offenses. Levene's Test (Levene, 1960) was used to check for the homogeneity of variances.

For the SP survey, a generalized linear mixed model (GLMM) with a binary logistic distribution was applied. To evaluate the association between the driver's propensity to drive after drinking and hypothetical combinations of penalties for drinkers, the presence of RBT, fine, DOPs, license disqualification period and imprisonment period with random disturbance were assumed in the proposed model. In addition to penalty levels, possible confounding factors, including gender, age, education level, personal income, past involvement in traffic offenses, traffic accidents and drink or drug driving, and driver's experience with RBTs were the fixed variables to be examined. Because every drinker was given six SP games, there were 3,018 records (503 drink drivers $\times 6$ ) in the proposed model.

In the proposed GLMM, $\boldsymbol{X} \beta$ is the systematic component and $\boldsymbol{Z} \alpha$ is the random component which are combined to form a linear predictor $\eta$ with a logit link function, specified as

$$
\eta=X \beta+Z \alpha
$$

where $\boldsymbol{X}$ and $\boldsymbol{Z}$ denote the vectors of possible contributory fixed and random variables, respectively. While $\beta$ and $\alpha$ denote the vector of the corresponding coefficient, which are estimated using the maximum likelihood approach. Then the vector of observations $y$ is obtained by adding a vector of residuals, as follows

$$
y=\eta+\varepsilon=\boldsymbol{X} \beta+\boldsymbol{Z} \alpha+\varepsilon
$$

To formulate the GLMM in this study, $y=1$ refers to one who would drive after drinking, and $y=0$ refers to one who would not drive after drinking. The probability function on the drivers' propensity to drive after drinking of the proposed GLMM by individual $i$ is therefore given by

$$
\pi\left(\eta_{i}\right)=\frac{e^{\eta_{i}}}{1+e^{\eta_{i}}}
$$


where a variance function was used to model the non-systematic variability of the model.

The influence of an attribute on propensity is revealed by the odds ratio $(O R)$, specified as

$$
\mathrm{OR}=\exp \left(\beta_{\mathrm{j}}\right)
$$

with $95 \%$ confidence intervals of $\left(\left(\beta_{\mathrm{j}}-1.96 \mathrm{~s}_{\beta_{\mathrm{j}}}\right),\left(\beta_{\mathrm{j}}+1.96 \mathrm{~s}_{\beta_{\mathrm{j}}}\right)\right)$, where $\mathrm{s}_{\beta_{\mathrm{j}}}$ is the standard error of the coefficient $\beta$. An odds ratio of greater than 1 indicates that the focal attribute leads to a higher propensity to drive after drinking and vice versa.

\section{Results}

\subsection{Drivers' perceptions of the deterrent effects of different penalties}

Table 4 and Figure 1 present the results of an independent samples $t$-test for the difference in the perceptions of drinkers and non-drinkers. The results of Levene's Test indicated that the variance of the dependent variables between groups was equal. As shown in Table 4, no significant difference could generally be observed between drinkers and non-drinkers for perceptions of the deterrent effect of the current penalties against drink-driving, except for the maximum fine $(t$-statistic $=-2.455, p<0.05)$ and the maximum duration of imprisonment $(t$ statistic $=-3.756, p<0.01)$ at the $5 \%$ and $1 \%$ levels of significance, respectively. Generally, the respondents considered that heavier penalty levels for drink-driving offenses should be sought, as the ratings for all existing penalties were all below 3: deduction of 10 DOPs (mean $=2.68, \mathrm{SD}=0.96$ ), maximum fine of HKD25000 (mean $=2.57, \mathrm{SD}=1.04$ ), maximum imprisonment for three years (mean $=2.93, \mathrm{SD}=1.12$ ), and minimum disqualification period of six months (mean $=2.37, \mathrm{SD}=0.97$ ). In particular, the drinkers considered the maximum imprisonment term of three years to be appropriate (mean $=3.03, \mathrm{SD}=1.12$ ), whereas nondrinkers considered a longer period of imprisonment to be suitable (mean $=2.70, \mathrm{SD}=1.10$ ).

Table 4 Independent samples $t$-test for perceptions of the deterrent effects of different penalties for drink driving

\begin{tabular}{l|cccc}
\hline Penalty & $\begin{array}{c}\text { Deduction of 10 } \\
\text { DOPs }\end{array}$ & $\begin{array}{c}\text { Maximum fine } \\
\text { of HKD 25,000 }\end{array}$ & $\begin{array}{c}\text { Maximum } \\
\text { imprisonment } \\
\text { for 3 years }\end{array}$ & $\begin{array}{c}\text { Minimum } \\
\text { disqualification } \\
\text { period of 6 } \\
\text { months }\end{array}$ \\
\hline & & Average score (standard deviation) \\
& & $2.63(1.04)$ & \\
\hline Drinkers & $2.72(0.94)$ & $3.03(1.12)$ & $2.41(0.99)$ \\
Non-drinkers & $2.59(0.98)$ & $2.43(1.02)$ & $2.70(1.10)$ & $2.27(0.94)$ \\
Absolute difference & 0.13 & 0.20 & 0.33 & 0.14 \\
Percentage difference & $5.0 \%$ & $8.2 \%$ & $12.2 \%$ & $6.2 \%$ \\
\hline$t$-Statistic & -1.732 & $-2.455^{*}$ & $-3.756^{* *}$ & -1.883 \\
\hline
\end{tabular}

${ }^{\dagger} 1$ - Too low; 2 - Low; 3 - Moderate; 4 - High; 5 - Too High.

*Statistically significant at the $5 \%$ level.

**Statistically significant at the $1 \%$ level. 


\section{The Appropriateness of Drink-Driving Penalties}

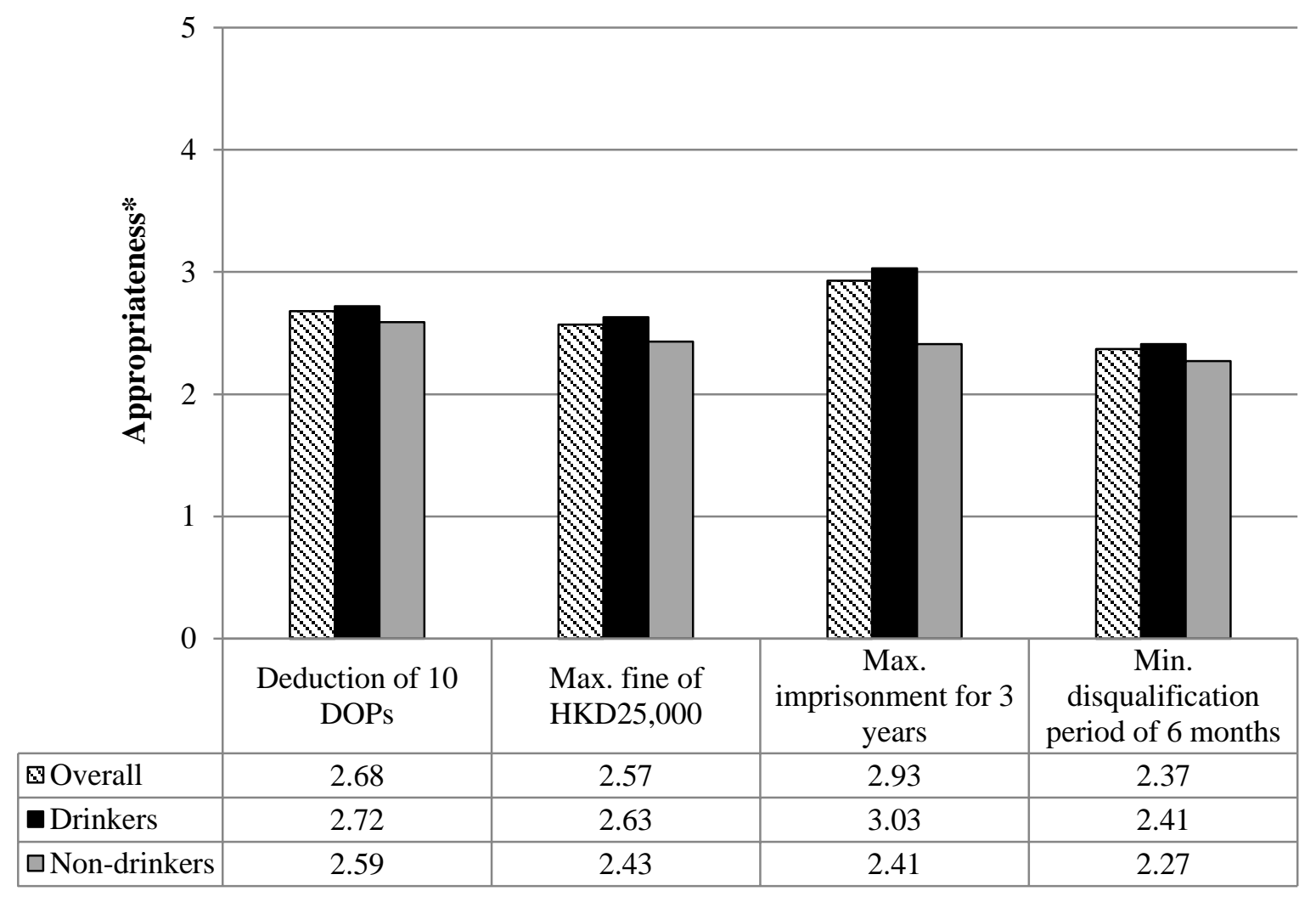

Figure 1 Drivers' perceptions of the deterrent effects of penalties

*1 - Too low; 2 - Low; 3 - Moderate; 4 - High; 5 - Too High.

\subsection{Drivers' propensity to commit a drink-driving offense}

The drivers' propensity to commit a drink-driving offense among the 503 drinkers was analyzed. Table 5 shows the results of the GLMM for the association between propensity to drink before driving and the possible contributory factors.

Table 5 GLMM results of the drivers' propensity to drink before driving $(n=3,018)$

\begin{tabular}{|c|c|c|c|c|c|c|c|}
\hline & \multirow{2}{*}{ Factor } & \multirow{2}{*}{ Attributes } & \multirow[t]{2}{*}{ Coefficient } & \multirow{2}{*}{ (t-statistic) } & \multirow{2}{*}{$\begin{array}{l}\text { Odds } \\
\text { ratio }\end{array}$} & \multicolumn{2}{|c|}{$95 \% \mathrm{CI}$} \\
\hline & & & & & & Lower & Upper \\
\hline & Fixed $v a$ & & & & & & \\
\hline \multirow[t]{10}{*}{ (a) } & Anti-dri & $g$ enforc & & & & & \\
\hline & - RBT & Yes & -0.870 & $(-5.338)^{* *}$ & 0.419 & 0.304 & 0.577 \\
\hline & & No & (Control) & & & & \\
\hline & - Fine $(\mathrm{I}$ & $00)$ & -0.056 & $(-5.773) * *$ & 0.946 & 0.928 & 0.964 \\
\hline & - Drivin & points & -0.050 & $(-2.772)^{* *}$ & 0.951 & 0.918 & 0.985 \\
\hline & Perce & ivalent fine & HKD893 & & & & \\
\hline & - Durati & nse disqualification & -0.016 & $(-2.074)^{*}$ & 0.984 & 0.969 & 0.999 \\
\hline & Perce & ivalent fine & HKD286 & & & & \\
\hline & - Durati & prisonment & -0.031 & $(-5.507)^{* *}$ & 0.969 & 0.959 & 0.980 \\
\hline & Perce & ivalent fine & HKD554 & & & & \\
\hline \multirow[t]{2}{*}{ (b) } & Confour & tors & & & & & \\
\hline & Gender & Male & 0.311 & $(0.993)$ & 1.365 & 0.710 & 2.622 \\
\hline
\end{tabular}




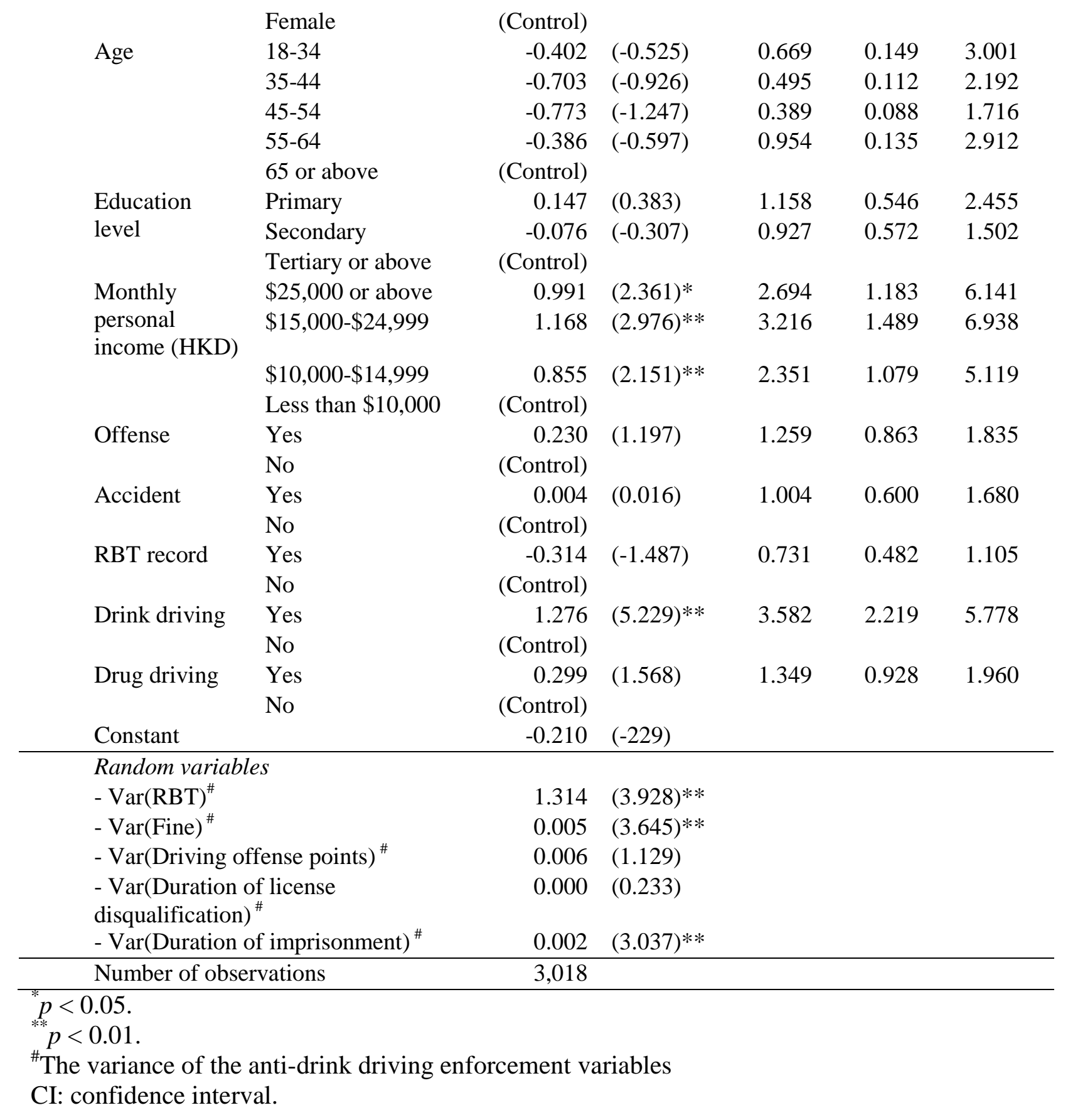

As shown in Table 5, the presence of an RBT checkpoint $(\mathrm{OR}=0.419,0.95 \mathrm{CI}=$ $[0.304,0.577])$ and increases in monetary fines $(\mathrm{OR}=0.946,0.95 \mathrm{CI}=[0.928,0.964])$, the license disqualification period $(\mathrm{OR}=0.984,0.95 \mathrm{CI}=[0.969,0.999])$, imprisonment period $(\mathrm{OR}=0.969,0.95 \mathrm{CI}=[0.959,0.980])$, and DOPs $(\mathrm{OR}=0.951,0.95 \mathrm{CI}=[0.918,0.985])$ all significantly reduced the propensity to drink before driving, at the $5 \%$ significance level. Besides, the parameters of presence of RBT, monetary fines, and imprisonments are normally distributed with variance of $1.314,0.005$ and 0.002 respectively, at the $1 \%$ level of significance.

The effects of driver demographics and involvement in traffic accidents and traffic offenses on the propensity to drink drive were marked. As Table 5 also shows, a higher personal income $(\$ 25,000$ or above: $\mathrm{OR}=2.694,0.95 \mathrm{CI}=[1.183,6.141] ; \$ 15,000-\$ 24,999$ : OR 
$=3.216,0.95 \mathrm{CI}=[1.489,6.938] ; \$ 10,000-\$ 14,999: \mathrm{OR}=2.351,0.95 \mathrm{CI}=[1.079,35.119])$ and drink driving in the past $(\mathrm{OR}=3.582,0.95 \mathrm{CI}=[2.219,5.778])$ notably increased drivers' propensity to drink before driving, all at the 5\% significance level.

\section{Discussion}

In this study, six SP games were used to measure the association between the type and level of penalties and their deterrent effect against drink driving. In addition, possible confounding factors that could be correlated to the likelihood of drink driving were explored. Many studies have shown that personal characteristics, including gender and age can have possible effects on drink-driving behavior in many Western countries (Begg et al., 2003; Glendon and Cernecca, 2003; Vanlaar, 2005; Peck et al., 2008; Jones and Holmgren, 2009; Fernandes et al., 2010; Moan and Rise, 2011). Moreover, a local study by Kim et al. (2010) revealed that the prevalence of drink driving among men in Hong Kong was five times higher than that among women. However, in contrast to the findings of previous studies, no evidence could be established for the effects of driver age and gender on the intention to commit drink-driving offenses in this study. Personal income was found to be a possible confounding factor to the association, whereas increase in personal income could increase the driver's propensity to commit a drink-driving offense. There is a general lack of research on the relation between personal income and alcohol consumption. However, Elgar et al. (2005) suggested that young people in high-income countries usually consume more alcohol than those in low-income countries, and it is reasonable to assume that people with higher incomes tend to spend more on luxury goods such as alcohol.

\subsection{Effect of the RBT as an enforcement measure}

The presence of an RBT checkpoint was correlated to a noticeable reduction of over $50 \%$ in drivers' intention to drink before driving. This is consistent with Ryeng's (2012) finding that strengthened enforcement measures are effective in deterring drivers from committing traffic offenses. The deterrent effects of an increase in the apprehension rate and the randomness of RBTs are well documented (Tay, 2005b). A review by Porter (2011) indicated that RBTs can result in a 13-27\% reduction in drink-driving-related accidents. Another study by Erke et al. (2009) suggested that the implementation of an RBT checkpoint can lead to at least a $17 \%$ reduction in alcohol-related accidents, based on crash statistics from countries including Australia, New Zealand, and the United States.

There is a general perception that drivers who have been subjected to an RBT may develop the perception of arrest certainty at RBT checkpoints, which increases their awareness of committing drink driving. However, no evidence was established for significant association between the propensity to drink drive of drivers and their RBT experience. In fact, there is an observed pattern of the diminishing effectiveness of RBT in recent years, with a 9\% increase in the number of drivers arrested in traffic accidents involving drink driving between 2011 and 2012 in Hong Kong (Hong Kong Police Force, 2012). Hence, further studies should be conducted to monitor the actual effect of RBT checkpoints in Hong Kong as a long-term road-safety strategy.

\subsection{Association between drink-driving propensity and penalty levels}


There is clear evidence to suggest that the joint force of appropriate enforcement measures and penalties is effective in deterring drivers from committing drink-driving offenses (Ross and Klette, 1995; Glendon and Cernecca, 2003; Houston and Richardson, 2004; Tay, 2005a). An increase in monetary fines in particular is effective in reducing convictions (Wagenaar et al., 2007; Wong et al., 2008). Monetary fines are considered a cost-efficient way of deterring drink driving. The negative correlation in this study between a driver's propensity to drink before driving and the level of monetary fine is consistent with previous findings. An increase in DOPs is another important factor in deterring drink driving. The DOP system (commonly known as the "demerit point system"), which was launched in Hong Kong during 1984, has been an effective means of improving driving behavior and enhancing road safety (Wong et al., 2004). The number of points incurred ranges from 3 to 10, depending on the severity of the offense. Drivers incurring 15 or more points within a period of two years are not allowed to drive for at least three months. The license disqualification period is extended to six months for repeat convictions (Transport Department, 2009b). Because the DOP system can lead to license disqualification, it should thus be effective in deterring drink driving.

We found that the severity of penalties correlated notably with deterrence of drink driving. Nevertheless, the deterrent effect of imprisonment could have been over emphasized because the perceived value for a unit increase (in months) in the period of imprisonment is only equivalent to a fine of HKD554. Apparently, a severe imprisonment period may not be as strong a deterrent against drink driving as are penalties. Indeed, Nichols and Ross (1990) had pointed out that the deterrent effect of license disqualification is stronger than that of other types of penalties. Wagenaar et al. (2007) also found that the deterrent effect of jail policies on drink-driving offenses in the United States was minimal.

The perception survey revealed that the drivers generally thought that the existing drink-driving penalty levels were somewhat too moderate. This indicates the need to introduce heavier penalties against drink driving in Hong Kong. However, it should be noted that the attribute levels chosen in the survey were the same or lower than the existing levels. This might have limited the ability to infer confidently about increasing the penalty levels. It could be worth exploring the diminishing effects of increased penalty levels by including higher attribute levels in future survey. Nevertheless, compared to enforcement measures such as the RBT, increases in penalty levels might have a marginal effect only on the driver propensity to drink before driving. About $14.0 \%$ of the drinkers claimed that they had driven after drinking in the previous three-month period (Table 1). In particular, these drivers could have a much higher propensity $(70 \%)$ to commit drink-driving than other nominal drivers. Some studies have admitted that reducing repeat convictions for drink driving will remain a challenge, regardless of further increases in penalty levels (Schechtman et al., 1999; Mathijssen, 2005; Lenton et al., 2010). Severe penalties and imprisonment may not be sustainable anti-drink-driving measures in the long run, and their introduction should only be as a last resort (Ross and Klette, 1995). It would be worthwhile to explore the possibilities of other drink-driving policy strategies to instill the correct behavior and attitudes in frequent drink-drivers, such as the use of mass media and public campaigns, the provision of mandatory driving improvement courses, and the installation of Alcolock ignition locks (Wong et al. 2004; Bjerre, 2005; Tay, 2005a; Fell and Voas, 2006; Lenton et al, 2010). The prevalence of drink driving could also be reduced by discouraging alcohol consumption. Studies of historical crash records have shown that the availability of alcoholic drinks can increase the risk of road crashes (Scribner et al., 1994; Gruenewald and Johnson, 2006; Treno 
et al., 2007). The government could increase the sales tax on, and thus the retail price of, alcohol as an alternative way of enhancing road safety in Hong Kong.

\section{Conclusions}

An attitudinal survey was conducted to examine the perceptions of drivers in Hong Kong about the existing penalties for drink-driving offenses, which include monetary fines, driver demerit points, license disqualification, and imprisonment. SP games were also used to measure the effects of possible penalties on drivers' propensity to drink before driving. The results of a mixed logistic regression model revealed that the presence of an RBT checkpoint and increases in DOPs and the periods of license disqualification and imprisonment all correlated positively with an increase in the deterrence of drink-driving. Hence, the existing penalties should be maintained and some considerations be given to increasing them moderately.

However, it should be noted that although appropriate enforcement strategies are essential to combat drink driving and enhance road safety levels in general, it may not be judicious to establish heavier penalty levels. Instead, it may be worth exploring the benefits of other remedial measures to increase public awareness of the risks of drink driving, including public education and campaigns, sliding-scale legislation, and a stricter blood alcohol limit. Research studies should be conducted to measure the effectiveness of these measures if comprehensive information on demographics and the driving habits of individual drivers become available in the future.

\section{Acknowledgements}

We gratefully acknowledge the Hong Kong Police Force for providing the RBT data. The research described here was supported by a Research Postgraduate Studentship, and a grant from the Research Grants Council of the Hong Kong Special Administrative Region, China (Project No. HKU 7188/11E).

\section{Appendix}

\section{QUESTIONNAIRE SAMPLE}

\section{Part A) Basic Information (Please tick as appropriate)}

1. Personal Information

(a) Gender:

$$
\square \text { Male } \quad \square \text { Female }
$$

(b) Age:

$\square$ 18-21 $\square 22-34 \square$ 35-44 $\square 45-54 \quad \square 55-64 \quad \square 65$ or above

(c) Weight:

Height: $\mathrm{cm}$

(d) Education: $\mathrm{lb}$ $\square$ Primary 
(e) Monthly personal salary:

$\square$ Less than $\$ 10,000$

$\square \$ 10,000-\$ 14,999$

$\square \$ 15,000-\$ 24,999$

$\square \$ 25,000$ or above

2. How many years have you had your driving license?

3. Did you obtain your driving license through the probationary driving license scheme (known as "P-plate")?
$\square$ Yes
$\square$ No

4. How many years of actual driving experience do you have?

(Actual driving experience refers to driving at least three times a month.)

5. Are you an occupational driver?
$\square$ Yes, full time
$\square$ Yes, part-time
$\square$ No

6. How many hours do you usually drive every week? hour(s)

\section{Part B) Questionnaire Information (Please tick as appropriate)}

7. Please provide information on the circumstances of when this questionnaire was delivered to you.

(a) Day of the week:
$\square$ Monday
$\square$ Tuesday
$\square$ Friday
$\square$ Saturday
$\square$ Wednesday
$\square$ Thursday
$\square$ Sunday

(b) Is it a public holiday?
$\square$ Yes
$\square$ No

(c) Time:
$\square$ 0700-1100 (morning)
$\square$ 1100-1500 (afternoon)
1500-1900 (evening)
口 1900-2300 (night)
$\checkmark$ 2300-0300 (midnight)
$\square$ 0300-0700 (dawn)

(d) Geographical area:

$\square$ Hong Kong Island $\square$ Kowloon (include Tseun Wan, Kwai Tsing, \& Tseung Kwan O

$\square$ New Territories \& North Lantau

(e) Vehicle class:

$\begin{array}{llll}\square \text { Private car } & \square \text { Taxi } & \square \text { Motorcycle } & \square \text { Public light bus } \\ \square \text { Coach } & \square \text { Franchised bus } & \square \text { Light van } & \square \text { Light good vehicle } \\ \square \text { Medium/Heavy } & \square \text { Container truck } & \square \text { Others (Please specify: } \\ \quad \text { goods vehicle } & & \end{array}$

(f) Have you drunk within the 4 hours before this questionnaire was delivered to you?

$\square$ No

$\square$ Yes (Please tick as appropriate and fill in the amount; you may choose more than one.)

$\circ$ Beer<smiles></smiles>

$\circ$ Table wine<smiles>[1H]</smiles>
can<smiles>C1CCC1</smiles>
$1 \quad$ glass $\circ$ Chinese rice wine

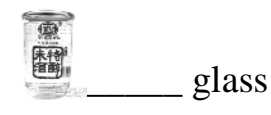

o Others (Please specify: glass 
○ Whisky

$$
29 \text { glass }
$$

(g) Is/are there any passenger(s) in the same vehicle?

$$
\square \text { No }
$$

$\square$ Yes (Please specify the number)
$\circ 1$
० 2
○ 4
$\circ 5-7$
$\circ 3$
$\circ 8$ or above

(h) What is your trip purpose? (You may choose more than one)
$\square$ Office
$\square$ School
$\square$ Shopping
$\square$ Work- or business-related
$\square$ Give a ride
$\square$ Entertainment
$\square$ Others (Please specify:

(i) Did you pass the random breath test conducted by the police?

$\square$ Yes

$\square$ No

\section{Part C) Traffic Offense-Related Information (Please tick as appropriate)}

8. Have you ever been prosecuted for any traffic offense in the past 12 months?

$\square$ Yes (Please tick as appropriate and fill in the number of times.)
$\circ$ Traffic sign offense time(s)
- Traffic signal offense time (s)
$\circ$ Speeding time(s)
$\circ$ Dangerous driving time(s)
- Careless driving time(s)
$\circ$ Drink driving time(s)
$\circ$ Drug driving time(s)
$\circ$ Other traffic offenses time(s) $\square$ No

9. Have you ever been involved in any traffic accidents in the past 12 months?

$\square$ Yes (Please tick as appropriate and fill in the number of times.)

$\circ$ Involved injury or mortality

$\circ$ Damage only time(s) $\square$ No time(s)

10. Have you ever been stopped by the police to conduct a random breath test in the past 12 months?
$\square 6$ times or more
$\square$ 3-5 times
$\square$ 1-2 times
$\square$ No

11. Have your relatives or friends ever been stopped by the police to conduct a random breath test in the past 12 months?

$\square$ Yes (Please specify the number of people given the test:

$\square$ No

12. Have you ever driven within 4 hours of drinking in the past 3 months?
$\square 6$ times or more
$\square$ 3-5 times
$\square$ 1-2 times
$\square$ No

13. Have you ever driven under the influence of drugs in the past 3 months?

(a) Narcotics or psychoactive drugs (e.g., heroin, ketamine, or amphetamines (known as "ice"), please specify:

$\square 6$ times or more $\quad \square 3-5$ times $\quad \square 1-2$ times $\quad \square$ No

(b) Prescription medicines

$\square 6$ times or more $\quad \square 3-5$ times $\quad \square 1-2$ times $\quad \square$ No 
Part D) Views Toward Anti-Drink Driving Measures (Please tick as appropriate)

14. Do you think the four existing penalties below are appropriate?

\begin{tabular}{lccccc} 
& Too low & Low & Moderate & High & Too high \\
& 1 & 2 & 3 & 4 & 5 \\
\hline (a) Deduct 10 Driving Offense Points (DOPs) & 0 & 0 & 0 & 0 & 0 \\
\hline (b) Maximum fine: $\$ 25,000$ & 0 & 0 & 0 & 0 & 0 \\
\hline (c) Maximum imprisonment: 3 years & 0 & 0 & 0 & 0 & 0 \\
\hline (d) Minimum driving disqualification period: 6 months & 0 & 0 & 0 & 0 & 0
\end{tabular}

15. What do you think of the effectiveness of the eight anti-drink-driving measures below?

Least

Most

effective

(a) Introducing sliding scale penalties system

12

○

5
(penalties will increase with driver's alcohol level)

(b) Increased penalties for repeat conviction

(c) Empower the police to conduct random breath tests

$\begin{array}{lllll}0 & 0 & 0 & 0 & 0\end{array}$

(d) Publicity through mass media

(e) Roadside slogans

(f) Leaflets (delivered at bars and gasoline stations)

(g) Mandatory Driving Improvement Course

(h) Introducing zero tolerance

16. Apart from the measures and penalties above, do you have any other recommendations?

17. Assume that you are now attending a gathering, e.g., wedding banquet or happy hour, in which alcoholic drinks will be served. Please answer the following questions.

Condition 1 Will you drink if you DO NOT NEED to drive after the gathering?

$\square$ No $\rightarrow$ «End of Questionnaire»

$\square$ Yes (Please tick as appropriate and fill in the amount; you may choose more than one.)

$\rightarrow$ «Please answer the question under Condition 2》

$\circ$ Beer

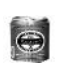

每

$\circ$ Chinese rice wine

$\circ$ Table wine

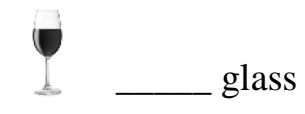

$\circ$ Others (Please specify:

$\circ$ Whisky

2 2. glass 
Condition 2 Given the following 6 combinations of different penalties to combat against drink driving, will you drink if you NEED to drive within 4 hours after the gathering (If yes, please indicate the amount)?

(i)

\begin{tabular}{l} 
No Random Breath Test \\
\hline - Fine: $\$ 5,000 \quad$ License disqualification: 0 months \\
- Imprisonment: 0 months
\end{tabular}

(ii) No Random Breath Test

- Fine: $\$ 10,000$ - Deduct: 10 DOPs

- License disqualification: 24 months

- Imprisonment: 12 months

(iii) No Random Breath Test

- Fine: $\$ 25,000$

- Deduct: 5 DOPs

- License disqualification: 24 months

- Imprisonment: 12 months

(iv) May be stopped to conduct a Random Breath Test

- Fine: $\$ 5,000 \quad$ Deduct: 0 DOP

- License disqualification: 24 months

- Imprisonment: 36 months

(v) May be stopped to conduct a Random Breath Test

- Fine: $\$ 10,000$ Deduct: 0 DOP

- License disqualification: 0 months

- Imprisonment: 12 months

(vi) May be stopped to conduct the Random Breath Test

- Fine: $\$ 25,000$ Deduct: 5 DOPs

- License disqualification: 0 months

- Imprisonment: 36 months
No

Yes (Comparing with Condition 1)

$\begin{array}{lllll}\circ 3 / 4 & \circ 1 / 2 & \circ 1 / 4 & \circ \text { the } & \circ \text { more } \\ \text { less } & \text { less } & \text { less } & \text { same } & \end{array}$

No

Yes (Comparing with Condition 1) $0^{3 / 4} \quad 0^{1 / 2} \quad 0^{1 / 4} \quad \circ$ the $\circ$ more less less less same

No

Yes (Comparing with Condition 1) $0^{3 / 4} \quad 0^{1 / 2} \quad 0^{1 / 4} \quad \circ$ the $\circ$ more less less less same

$\square$ No

Yes (Comparing with Condition 1) $\circ 3 / 4 \quad \circ 1 / 2 \quad \circ 1 \frac{1}{4} \quad \circ$ the $\circ$ more less less less same

No

Yes (Comparing with Condition 1) $\circ 3 / 4 \quad \circ 1 / 2 \quad \circ 1 \frac{1}{4} \quad \circ$ the $\circ$ more less less less same

$\square$ No

Yes (Comparing with Condition 1) $\circ 3 / 4 \quad 0^{1 / 2} \quad 0^{1 / 4} \quad \circ$ the $\circ$ more less less less same

« End of Questionnaire»

Thank you for your valuable time. Please return the completed questionnaire script with the envelope provided. 


\section{References}

Bajwa S., Bekhor S., Kuwahara M., Chung E. 2008. "Discrete choise modelling of combined mode and departure time." Transportmetrica, 4(2): 155-177,

Begg D.J., Langley J.D., and Stephenson S. 2003. "Identifying factors that predict persistent driving after drinking, unsafe driving after drinking, and driving after using cannabis among young adults." Accident Analysis and Prevention 35: 669-675.

Bjerre B. 2005. "Primary and secondary prevention of drink driving by the use of alcolock device and program: Swedish experiences." Accident Analysis and Prevention 37: 11451152.

Bliemer M.C.J., and Rose J.M. 2011. "Experimental design influences on stated choice outputs: An empirical study in air travel choice." Transportation Research Part A: Policy and Practice 45(1): 63-79.

Briscoe S. 2004. "Raising the bar: can increased statutory penalties deter drink-drivers?" Accident Analysis and Prevention 36(5): 919-929.

Cameron P.A., Rainer T.H., and Mak P. 2004. "Motor vehicle deaths in Hong Kong: opportunities for improvement." Journal of Trauma, 56(4): 890-893.

Department of Health. 2011. "Drinking Behaviour of Adults in Hong Kong (aged 18-64)" Accessed June 17, 2013.

http://www.change4health.gov.hk/en/alcohol_aware/figures/behaviour/adults/index.html

Department of Health. 2011. "Action plan to reduce alcohol-related harm in Hong Kong. Chapter 2." Accessed August 4, 2012.

http://www.change4health.gov.hk/en/strategic_framework/structure/working_group_on_ah/a ction_plan

Elgar F.J., Roberts C., Parry-Langdon N., Boyce W. 2005. "Income inequality and alcohol use: a multilevel analysis of drinking and drunkenness in adolescents in 34 countries." European Journal of Public Health, 15(5): 245-250.

Elvik R., and Christensen P. 2007. "The deterrent effect of increasing fixed penalties for traffic offences: the Norwegian experience." Journal of Safety Research, 38: 689-695.

Erke A., Goldenbeld C., and Vaa T. 2009. "The effects of drink-driving checkpoints on crashes--a meta-analysis." Accident Analysis and Prevention, 41(5): 914-923.

Fell J.C., and Voas R.B. 2006. "The effectiveness of reducing illegal blood alcohol concentration (BAC) limits for driving: Evidence for lowering the limit to .05 BAC." Journal of Safety Research, 37(3): 233-243.

Fernandes R., Hatfield J., and Soames Job R.F. 2010. "A systematic investigation of the differential predictors for speeding, drink-driving, driving while fatigued, and not wearing a seat belt, among young drivers." Transportation Research Part F: Traffic Psychology and Behaviour, 13(3): 179-196.

Glendon A.L., and Cernecca L. 2003. "Young drivers' responses to anti-speeding and antidrink-driving messages." Transportation Research Part F: Traffic Psychology and Behaviour, 6(3): 197-216.

Goldenbeld C., and Schagen I.V. 2005. "The effects of speed enforcement with mobile radar on speed and accidents: an evaluation study on rural roads in the Dutch province Friesland." Accident Analysis and Prevention, 37(6): 1135-1144.

Gruenewald P.J., and Johnson F.W. 2006 "The stability and reliability of self-reported drinking measures." Journal of Studies on Alcohol, 67(5): 738-745.

Hong Kong Police Force. 2010. Review of drink driving following the implementation of random breath testing. Unpublished report. Hong Kong Police Force of HKSAR.

Hong Kong Police Force. 2012. "RSC and TBHQ remind the public not to drive after drinking during festive season." Accessed February 22, 2013. 
http://www.police.gov.hk/ppp_en/05_traffic_matters/rs_130108.html

Houston D.J. and Richardson L.E. 2004. "Drinking-and-driving in America: a test of behavioural assumptions underlying public policy." Political Research Quarterly, 57(1): 53-64.

Jones A.W., and Holmgren A. 2009. "Age and gender differences in blood-alcohol concentration in apprehended drivers in relation to amounts of alcohol consumed." Forensic Science International, 188: 40-45.

Kim J.H., Lee S., Chan K.W.C., Lau J., Tsang A., Griffiths S.M. 2010. “A population-based study on the prevalence and correlates of drinking and driving in Hong Kong." Accident Analysis and Prevention, 42(4): 994-1002.

Lapham S.C., and Todd M. 2012. "Do deterrence and social-control theories predict driving after drinking 15 years after a DWI conviction?" Accident Analysis and Prevention, 45(4): 142-151.

Lenton S., Fetherston J., and Cercarelli R. 2010. "Recidivist drink drivers' self-reported reasons for driving whilst unlicensed--a qualitative analysis." Accident Analysis and Prevention, 42(2): 637-644.

Levene H. 1960. Contributions to Probability and Statistics: Essays in Honor of Harold Hotelling, I. Olkin et al. eds. Stanford, CA: Stanford University Press: 278-292.

Li Y.C., Sze N.N., Wong S.C., Tsui K.L., So F.L. 2013a. "Effects of drink driving on crash risk based on random breath test data." Hong Kong Journal of Emergency Medicine, 20(3): 146-154.

Li Y.C., Sze N.N., Wong S.C. 2013b. Spatial-temporal analysis of drink-driving patterns in Hong Kong. Accident Analysis and Prevention, 59: 415-424.

Mathijssen M.P.M. 2005. "Drink driving policy and road safety in the Netherlands: a retrospective analysis." Transportation Research Part E: Logistics and Transportation Review, 41(5): 395-408.

Moan I.S., and Rise J. 2011. "Predicting intentions not to 'drink and drive' using an extended version of the theory of planned behaviour." Accident Analysis and Prevention, 43(4): 1378-1384.

Montag J. 2010. "Radical change in traffic law: effects on road safety in the Czech Republic." 5th Annual Conference on Empirical Legal Studies Paper. Accessed July 10, 2013. http://dx.doi.org/10.2139/ssrn.1595882.

Montgomery D.C. 2001. Design and Analysis of Experiments (5th ed.). New York: John Wiley \& Sons, Inc.

Nichols J.L., and Ross H.L. 1990. "The effectiveness of legal sanctions in dealing with drinking drivers." National Criminal Justice Reference Service, 6(2): 33-60.

Peck R.C., Gebers M.A., Voas R.B., Romano E. 2008. "The relationship between blood alcohol concentration (BAC), age and crash risk." Journal of Safety Research, 39: 311319.

Porter B.E. 2011. "Chapter 31 - Enforcement." Handbook of Traffic Psychology, 441-453.

Rose J.M., Hensher D.A., Greene W.H. , Washington S.P. 2012. "Attribute exclusion strategies in airline choice: accounting for exogenous information on decision maker processing strategies in models of discrete choice." Transportmetrica, 8(5): 344-360.

Ross H.L. 1984. Deterring the drinking driver: legal policy and social control (revised and updated edition). Lexington: Lexington Books.

Ross H.L., and Klette H. 1995. "Abandonment of mandatory jail for impaired drivers in Norway and Sweden." Accident Analysis and Prevention, 27(2): 151-157.

Ryeng E.O. 2012. "The effect of sanctions and police enforcement on drivers' choice of speed." Accident Analysis and Prevention, 45: 446-454. 
Ruhm C.J. 1996. "Alcohol policies and highway safety fatalities." Journal of Health Economics, 15: 435-454.

Schechtman E., Shinar D., and Compton R.C. 1999. "The relationship between drinking habits and safe driving behaviors." Transportation Research Part F: Traffic Psychology and Behaviour, 2(1): 15-26.

Scribner R.A., MacKinnon D.P., and Dwyer J.H. 1994. "Alcohol outlet density and motor vehicle crashes in Los Angeles County cities." Journal of Studies on Alcohol, 55(4): 447453.

Tay R. 2005a. "Drink driving enforcement and publicity campaigns: are the policy recommendations sensitive to model specification?" Accident Analysis and Prevention, 37(2): 259-266.

Tay R. 2005b. "General and specific deterrent effects of traffic enforcement: do we have to catch offenders to reduce crashes?" Journal of Transport Economics and Policy, 39(2): 209-223.

Transport Department. 2009a. Road traffic accident statistics, year 2007 to year 2011, Transport Department of Hong Kong. Accessed July 29, 2012.

http://www.td.gov.hk/en/road_safety/road_traffic_accident_statistics/index.html

Transport Department. 2009b. Drink driving - the penalties, Transport Department of Hong Kong. Accessed July 29, 2012.

http://www.td.gov.hk/en/road_safety/drink_driving/the_penalties_/ index.html

Treno A.J., Johnson F.W., Remer L.G., Gruenewald P.J. 2007. "The impact of outlet densities on alcohol-related crashes: a spatial panel approach." Accident Analysis and Prevention, 39(5): 894-901.

Tsui K.L., Sze N.N., So F.L., Wong S.C. 2010. "Association between drink driving and severity of crash injuries to road users." Hong Kong Journal of Emergency Medicine, 17(1): 4-39.

Vanlaar W. 2005. "Drink driving in Belgium: results from the third and improved roadside survey." Accident Analysis and Prevention, 37(3): 391-397.

Wagenaar A.C., Maldonado-Molina M.M., Erickson D.J., Ma L., Tobler A.L., Komro K.A. 2007. "General deterrence effects of U.S. statutory DUI fine and jail penalties: long-term follow-up in 32 states." Accident Analysis and Prevention, 39(5): 982-994.

Wang D.G., and Li J.K. 2002. "Handling large numbers of attributes and/or large numbers of levels in conjoint experiments." Geographical Analysis, 34: 350-362.

Wang D.G., and Li P.F. 2005. "Does uniform design really work in stated choice modeling? A simulation study." Transportmetrica, 1(3): 209-221.

WHO 2007. Drinking and driving: a road safety manual for decision-makers and practitioners. Geneva, Global Road Safety Partnership.

Wong S.C., Leung B.S.Y., Loo B.P.Y., Hung W.T., Lo H.K. 2004. "A qualitative assessment methodology for road safety policy strategies." Accident Analysis and Prevention, 36(2): 281-293.

Wong S.C., Wong C.W., and Sze N.N. 2008. "Attitudes of public light bus drivers to penalties to combat red light violations in Hong Kong." Transport Policy, 15: 43-54. 